\title{
Growth and Electrochemical Stability of Compact Tantalum Oxides Obtained in Different Electrolytes for Biomedical Applications
}

\author{
Ricardo Sanson Namur ${ }^{a}$, Karla Miriam Reyes ${ }^{a}$, Cláudia Eliana Bruno Marino ${ }^{b *}$ \\ ${ }^{a}$ Programa de Pós-graduação em Ciências e Engenharia de Materiais - PIPE, Universidade \\ Federal do Paraná - UFPR, Centro Politécnico, CEP 81531-990, Curitiba, PR, Brasil \\ ${ }^{b}$ Laboratório de Biomateriais e Eletroquímica, Departamento de Engenharia Mecânica, Universidade \\ Federal do Paraná - UFPR, Centro Politécnico, CEP 81531-990, Curitiba, PR, Brasil
}

Received: November 10, 2014; Revised: July 28, 2015

\begin{abstract}
Tantalum has been cited to have many biomaterial applications, exhibiting biocompatibility and outstanding corrosion resistance. Tantalum may be covered with tantalum oxide using the electrochemical process of anodic oxidation. The oxide surface is known to be bioactive and more corrosion resistant. In this research, compact tantalum oxide films were obtained by potentiostatic and potentiodynamic methods in $\mathrm{H}_{2} \mathrm{SO}_{4}$ and $\mathrm{H}_{3} \mathrm{PO}_{4}\left(1 \mathrm{~mol} . \mathrm{L}^{-1}\right)$ electrolytes. By XPS analysis the stoichiometry $\mathrm{Ta}_{2} \mathrm{O}_{5}$ was detected. The thermodynamic stability of those oxides was compared and the results indicated that $\mathrm{Ta}_{2} \mathrm{O}_{5}$ obtained in $\mathrm{H}_{2} \mathrm{SO}_{4}$ has higher thermodynamic stability than $\mathrm{Ta}_{2} \mathrm{O}_{5}$ obtained in $\mathrm{H}_{3} \mathrm{PO}_{4}$. The incorporation of $\left(\mathrm{PO}_{4}\right)^{3-}$ ions and the formation of a bilayer oxide are responsible for the reduced stability. Also, the better control of chemical kinetic of oxide formation allows potentiodynamic oxides to be more stable. $\mathrm{Ta}_{2} \mathrm{O}_{5}$ shows spontaneous dissolution in artificial blood, nevertheless, it remains stable even after 60 days of immersion. By scratching tests was possible to notice that $\mathrm{Ta}_{2} \mathrm{O}_{5}$ is highly adherent to the tantalum metallic substrate and by mechanical indentation was possible to measure a lower elastic modulus for the $\mathrm{Ta}_{2} \mathrm{O}_{5}$ than the metallic substrate, what can be considered as distinguished properties for biomedical applications.
\end{abstract}

Keywords: biomaterial, tantalum, anodic oxide, electrochemical stability

\section{Introduction}

Metals used in biomedical appliances must show particular properties, depending on its specific utilization. The main property to be considered is biocompatibility, followed by corrosion resistance and mechanical properties. For being highly resistant to corrosion in corporeal media, metallic titanium and its alloys have been mostly used ${ }^{1}$. Concerning biomaterials, researches regarding tantalum are motivated by its great corrosion resistance ${ }^{2}$. Nowadays, many researchers $\mathrm{s}^{3-5}$ are studying Ti-Ta alloys since its lower density, lower cost and superior corrosion resistance, as compared to titanium, makes them extremely promising. Although tantalum can be used in its metallic form, the natural oxide $\left(\mathrm{Ta}_{2} \mathrm{O}_{5}\right)$ may improve its bioactive response and chemical attack resistance ${ }^{6}$. The electrochemical method of anodic oxidation is one the most versatile process towards the growth of oxides on valve metals like tantalum and titanium ${ }^{7}$. Some authors ${ }^{8,9}$ have already studied the influence of the anodization parameters in anodic oxides properties. About Ti-Zr alloys, higher stability oxides were obtained when higher potentials were applied $^{8}$. Also, higher or lower thermodynamical stabilities were achieved in different acidic electrolytes ${ }^{8}$. On titanium surfaces, thicker oxides were obtained in higher polarization potentials ${ }^{9}$.

The mechanism and kinetics of $\mathrm{Ta}_{2} \mathrm{O}_{5}$ formation in aqueous solutions were discussed by many researches ${ }^{10-14}$, and

*e-mail: claudiamarino@ufpr.br most of these studies consider the oxide formation in dilute acidic electrolytes of $\mathrm{H}_{2} \mathrm{SO}_{4}$ and $\mathrm{H}_{3} \mathrm{PO}_{4}$. In these acids, $\mathrm{Ta}_{2} \mathrm{O}_{5}$ may incorporate electrolyte anions as $\left(\mathrm{SO}_{4}\right)^{2-}$ or $\left(\mathrm{PO}_{4}\right)^{3-}$ to its structure besides of $\mathrm{O}^{2-}$, wherein the phosphate ion are the most likely to be incorporated ${ }^{10,12}$. Several properties of tantalum oxide may be modified by the incorporation of electrolyte anions, mainly its chemical stability and the formation of a bilayer oxide ${ }^{12,13}$.

This research had the purpose to compare the thermodynamic stability of tantalum oxides grown by different anodization methods and potentials in dilute $\mathrm{H}_{2} \mathrm{SO}_{4}$ and $\mathrm{H}_{3} \mathrm{PO}_{4}$, as well as the spontaneous dissolution resistance in artificial blood media by open-circuit potential (OCP) method. This research also evaluated mechanical properties, as elastic modulus and scratching resistance, for the grown oxide.

\section{Experimental}

Samples of tantalum $(99.9 \%+)$ measuring $1 \mathrm{~mm}$ thick, $2 \mathrm{~cm}^{2}$ were provided by Sigma-Aldrich Brasil Ltda. For surface preparation, the samples were grounded up to grid 600 sandpaper and then sonicated in three sequential baths: pure acetone, isopropyl alcohol and distilled water (15 minutes each).

The anodization processes were made in a conventional three electrode electrochemical cell. The working electrode was pure tantalum with $0.28 \mathrm{~cm}^{2}$ of exposed area to the 
electrolyte. A spiral platinum wire was used as counter electrode and all potentials were measured against a saturated calomel electrode (SCE). Working and counter electrode were connected to a Power Supply (Minipa - MPL 1305M) for potentiostatic oxidation at stationary potentials of $5 \mathrm{~V}$ and $20 \mathrm{~V}$ during $1 \mathrm{~h}$. For potentiodynamic oxidation a potential sweep between -1.0 and $5.0 \mathrm{~V}(50 \mathrm{mV} / \mathrm{s})$ was used in a potentiostat-galvanostat (Microquímica - MQPG-01). Two acidic electrolytes were used: $\mathrm{H}_{2} \mathrm{SO}_{4}\left(1 \mathrm{~mol} . \mathrm{L}^{-1}\right)$ and $\mathrm{H}_{3} \mathrm{PO}_{4}\left(1 \mathrm{~mol} \cdot \mathrm{L}^{-1}\right)$. All oxidation experiments were performed at room temperature. To characterize the surface oxide, XPS (X-ray Photoelectron Spectroscopy) analysis were performed using a VG Microtech ESCA3000 spectrometer having an $\mathrm{A} 1 \mathrm{~K} \alpha \mathrm{X}$-Ray source in $3.10^{-8} \mathrm{~Pa}$ pressure and $20 \mathrm{eV}$ energy band.

To compare the electrochemical stability of the new oxidized surfaces, OCP (Open Circuit Potential) of all surfaces was measured. Also, the dissolution process of oxidized surfaces was studied before and after immersion in artificial blood by different periods at $37^{\circ} \mathrm{C}$. The stabilization time of OCP potentials was fixed in 90 minutes. These potentials were measured in PBS (Phosphate Buffer Solution) media that contains $\mathrm{NaCl} 8.0$ g. $\mathrm{L}^{-1}, \mathrm{KCl}, 0.2$ g.L. $\mathrm{L}^{-1}, \mathrm{Na}_{2} \mathrm{HPO}_{4}$ 1.15 g. $\mathrm{L}^{-1}$ and $\mathrm{KH}_{2} \mathrm{PO}_{4} 0.2$ g. $\mathrm{L}^{-1}$, commonly used solution in electrochemical tests. Samples were exposed to artificial
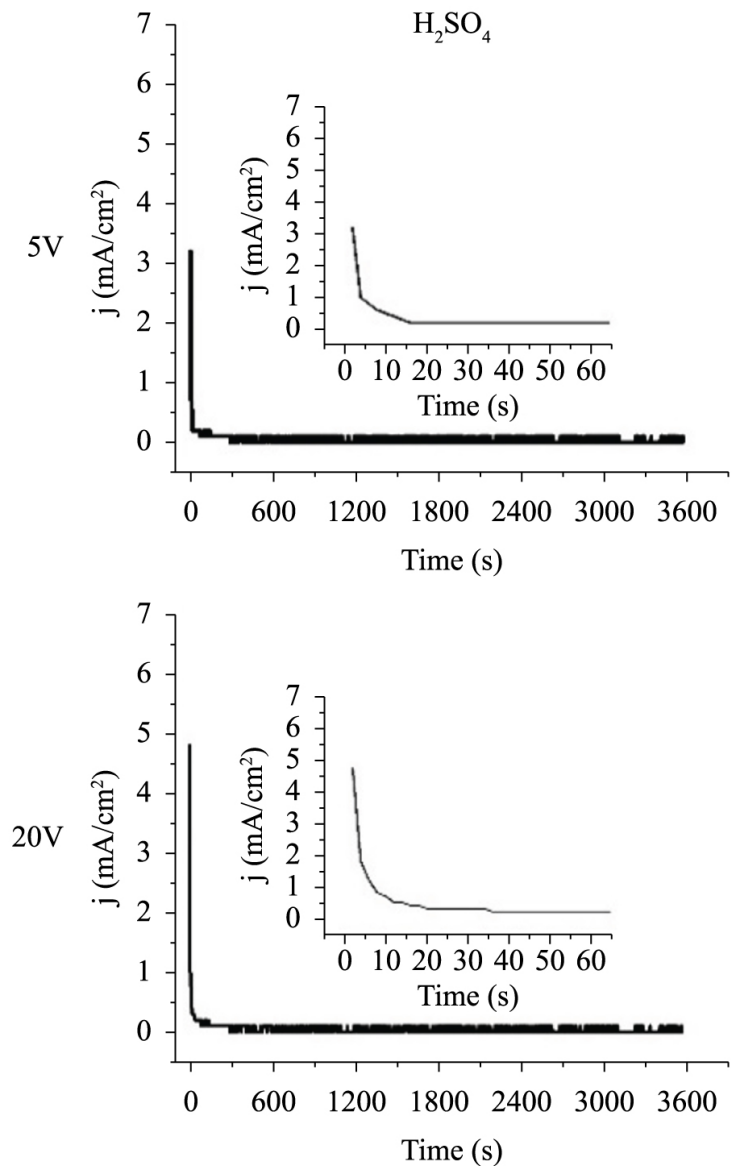

blood (at $37^{\circ} \mathrm{C}$ ) during 15, 30 and 60 days. Artificial blood is composed of $\mathrm{NaCl} 6.80 \mathrm{~g} . \mathrm{L}^{-1}, \mathrm{KCl} 0.40 \mathrm{~g} . \mathrm{L}^{-1}, \mathrm{CaCl}_{2} \cdot \mathrm{H}_{2} \mathrm{O}$ 0.20 g.L $\mathrm{L}^{-1}, \mathrm{NaH}_{2} \mathrm{PO}_{4} \cdot \mathrm{H}_{2} \mathrm{O} 0.02$ g.L $\mathrm{L}^{-1}, \mathrm{Na}_{2} \mathrm{HPO}_{4} \cdot \mathrm{H}_{2} \mathrm{O} 0.126$ g.L $\mathrm{L}^{-1}$, $\mathrm{MgSO}_{4} 0.10$ g.L. $\mathrm{NaHCO}_{3} 2.20$ g.L $\mathrm{L}^{-1}(\mathrm{pH} \sim 7.45)$. PBS and artificial blood solutions have their chemical composition described in ASTM - F2129-08.

To evaluate the mechanical properties (elastic modulus and adherence to substrate) a MTS instruments - Nano Indenter XP was used. Instrumented indentation measures were made with a Berkovich tip with a maximum load of $1 \mathrm{gf}$ with eight complete cycles of loading and unloading in a matrix of 25 sites. The mechanical properties were collected from analyses of load-displacement data using the Oliver-Pharr method ${ }^{14}$. The scratching tests were made using a Berkovich tip and three maximum loads: 10, 30 and $50 \mathrm{mN}$ with three scratches in each load. Scratches were made in ramp with a constant displacement speed of $10 \mu \mathrm{m} / \mathrm{s}$ along $600 \mu \mathrm{m}$, it was used scanning electron microscopy to analyze the scratches.

\section{Results and Discussion}

By anodic oxidation, compact tantalum oxides were obtained on the working electrodes. All the chronoamperometric profiles (Figure 1) showed the typical behavior of valve
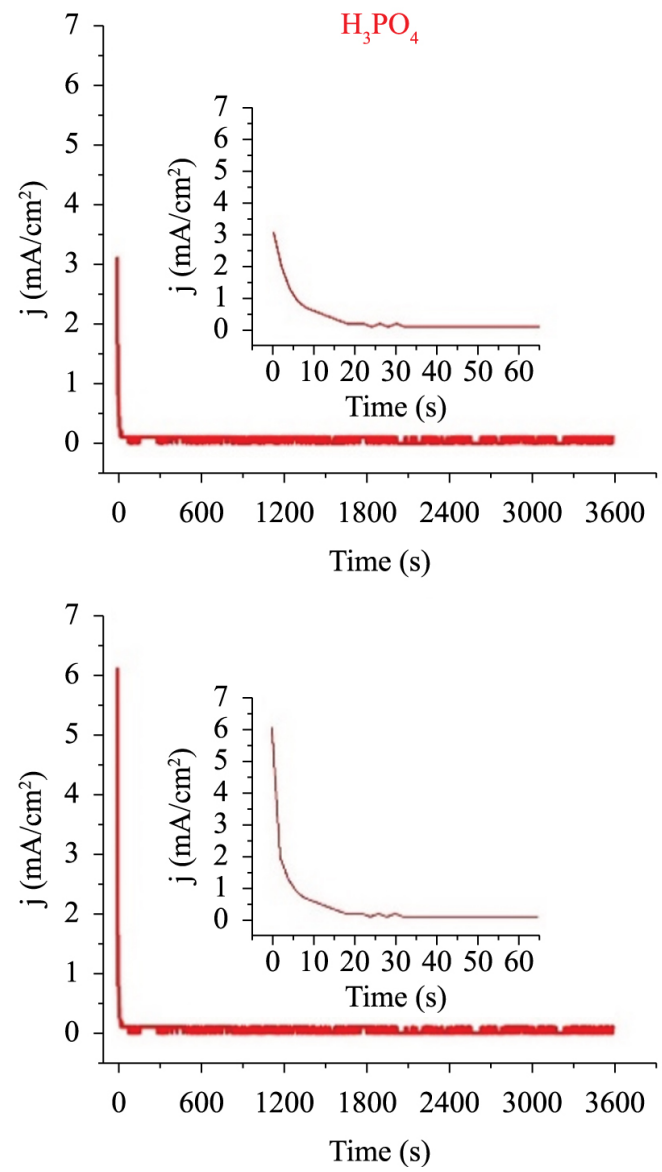

Figure 1. Chronoamperometric profiles for tantalum oxides obtaining at $5 \mathrm{~V}$ and $20 \mathrm{~V}$ in $\mathrm{H}_{2} \mathrm{SO}_{4}$ and $\mathrm{H}_{3} \mathrm{PO}_{4}\left(1\right.$ mol.L $\left.\mathrm{L}^{-1}\right)$. Insets represents the first seconds of the process. 
metals, with a maximum of current density in the very beginning of the process, associated to the fast formation of an insulating oxide. As the process is continued, the current density undergoes a sudden decay due to the oxide insulating behavior and reaches a stable plateau of $\mathrm{mA}$ or even $\mu \mathrm{A}$, where reactions of oxidation and reduction still occurs in slower kinetics, since migration of ions is needed to the thickening of the oxide layer. The anodization was the only process noticed. As all chronoamperometric profiles of Figure 1 are very similar, it's assumable that the kinetics of formation of the potentiostatic tantalum oxide is mainly influenced by the method of anodization and the applied potential, whereas different electrolytes, containing $\left(\mathrm{PO}_{4}\right)^{3-}$ or $\left(\mathrm{SO}_{4}\right)^{2-}$ ions, seems to have similar chemical kinetics. The potential sweep for potentiodynamic method for both electrolytes is also very similar (Figure 2 and Figure 3), showing a sudden inversion of current density from cathodic to anodic, with a current density peak in approximately $0.25 \mathrm{~V}$ for $\mathrm{H}_{2} \mathrm{SO}_{4}$ and $0.02 \mathrm{~V}$ for $\mathrm{H}_{3} \mathrm{PO}_{4}$, and a plateau until $5 \mathrm{~V}$ for both electrolytes. The displacement between peaks may be related to the greater oxidant behavior of $\mathrm{H}_{3} \mathrm{PO}_{4}$

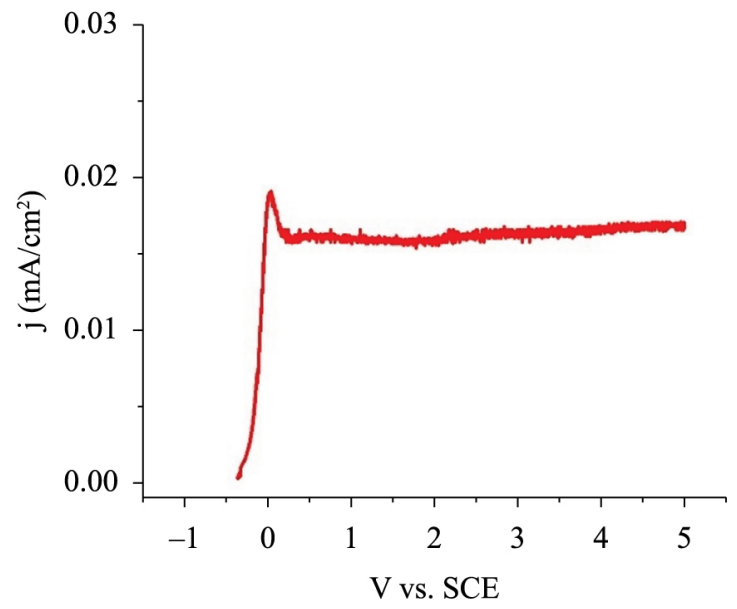

Figure 2. Potential sweep profile for tantalum oxide obtained up to $5 \mathrm{~V}(50 \mathrm{mV} / \mathrm{s})$ in $\mathrm{H}_{2} \mathrm{SO}_{4}\left(1 \mathrm{~mol} . \mathrm{L}^{-1}\right)$.

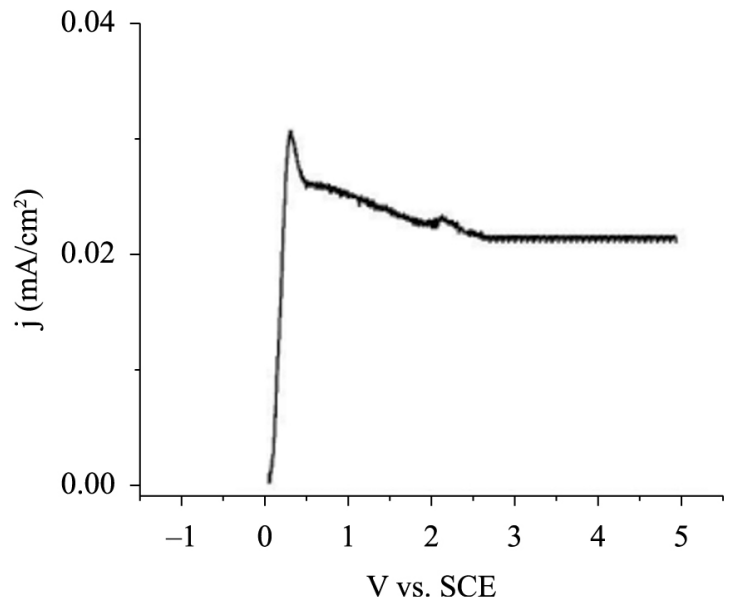

Figure 3. Potential sweep profile for tantalum oxide obtained up to $5 \mathrm{~V}(50 \mathrm{mV} / \mathrm{s})$ in $\mathrm{H}_{3} \mathrm{PO}_{4}\left(1 \mathrm{~mol} \cdot \mathrm{L}^{-1}\right)$. due to its higher dissociation in aqueous media. Those behaviors indicate the formation of an oxide that features high electrical resistance.

XPS analysis of the oxidized samples indicated the $\mathrm{Ta}_{2} \mathrm{O}_{5}$ stoichiometry as the superficial oxide, independently of the electrolyte. Both samples presented peaks referring to tantalum and oxygen bonded to each other in the stoichiometry $\mathrm{Ta}_{2} \mathrm{O}_{5}^{[15,16]}$ (Figure 4 and Figure 5). Tantalum in $\mathrm{Ta} / \mathrm{Ta}_{2} \mathrm{O}_{5}-\mathrm{H}_{2} \mathrm{SO}_{4}$ was detected by a doublet in approximately $26 \mathrm{eV}$ and oxygen by a singlet in approximately $530 \mathrm{eV}$. Similarly, $\mathrm{Ta} / \mathrm{Ta}_{2} \mathrm{O}_{5}-\mathrm{H}_{3} \mathrm{PO}_{4}$ presented a doublet associated to tantalum in approximately $26 \mathrm{eV}$ and a singlet to oxygen in approximately $530 \mathrm{eV}$. The sample oxidized in $\mathrm{H}_{3} \mathrm{PO}_{4}$ exhibited also a peak in approximately $133 \mathrm{eV}$ associated to phosphorus bonded to oxygen, indicating that a mixed oxide of tantalum and phosphorus may be formed ${ }^{17,18}$ (Figure 5). This result indicates that electrolyte anions, mainly phosphates, are indeed incorporated to the forming oxide during anodization.

In order to compare the electrochemical stability of the tantalum oxides obtained by different electrochemical methods, electrolytes and potentials, OCP tests were made and the results are shown in Table 1. Oxide growth methods differ on its electrochemical parameters control, mainly the chemical kinetics of oxide formation ${ }^{19}$. The uniform formation kinetic
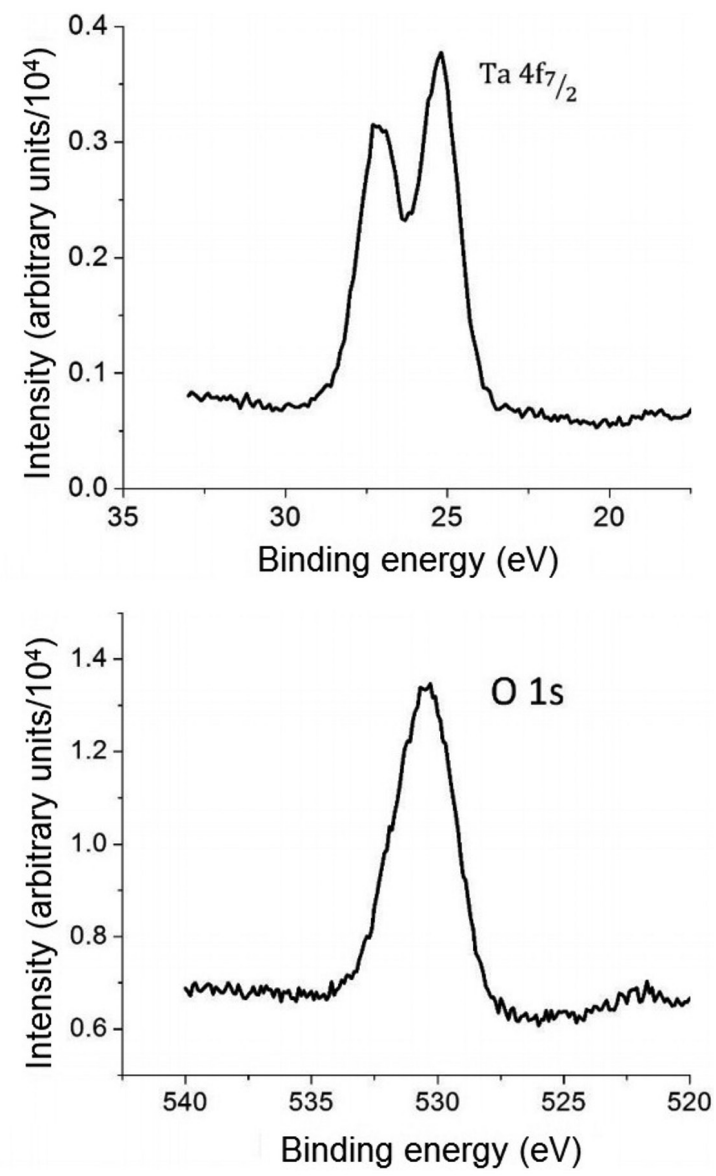

Figure 4. XPS spectra for tantalum and oxygen of the sample of tantalum oxide obtained in $\mathrm{H}_{2} \mathrm{SO}_{4}$. 

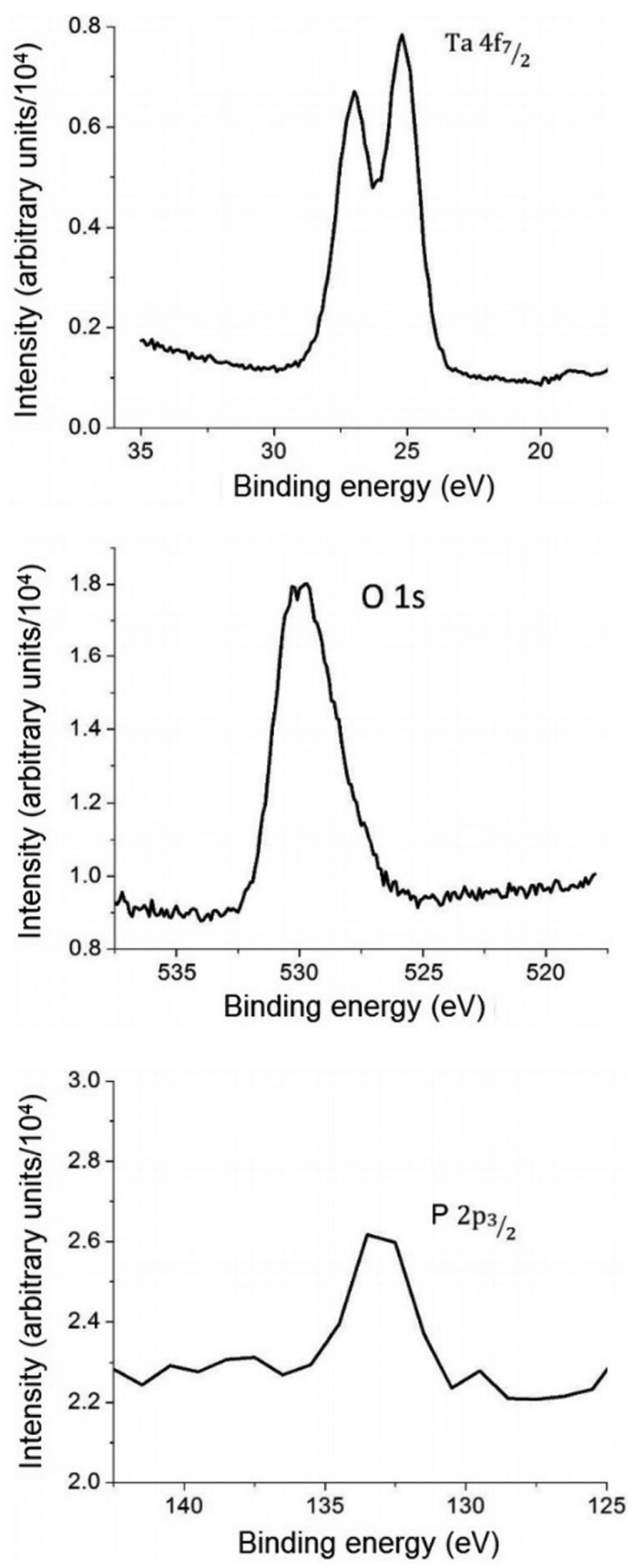

Figure 5. XPS spectra for tantalum, oxygen and phosphorus of the sample of tantalum oxide obtained in $\mathrm{H}_{3} \mathrm{PO}_{4}$.

Table 1. OCP values for tantalum oxides grown by potentiostatic and potentiodynamic methods in $\mathrm{H}_{2} \mathrm{SO}_{4}$ and $\mathrm{H}_{3} \mathrm{PO}_{4}\left(1\right.$ mol.L $\left.\mathrm{L}^{-1}\right)$.

\begin{tabular}{|c|c|c|}
\hline \multirow{2}{*}{ Method } & \multicolumn{2}{|c|}{ OCP / mV (vs. SCE) } \\
\hline & $\mathrm{H}_{3} \mathrm{PO}_{4}\left(1 \mathrm{~mol} . \mathrm{L}^{-1}\right)$ & $\mathrm{H}_{2} \mathrm{SO}_{4}\left(1 \mathrm{~mol} . \mathrm{L}^{-1}\right)$ \\
\hline $\begin{array}{l}\text { Potentiostatic } \\
20 \mathrm{~V}(1 \mathrm{~h})\end{array}$ & -17.3 & -5.42 \\
\hline $\begin{array}{l}\text { Potentiostatic } \\
5 \mathrm{~V}(1 \mathrm{~h})\end{array}$ & -67.2 & -42.3 \\
\hline $\begin{array}{l}\text { Potentiodynamic } \\
\qquad \mathrm{Ei}=-1.0 \mathrm{~V} \\
\mathrm{Ef}=5.0 \mathrm{~V}\end{array}$ & -38.4 & -22.8 \\
\hline
\end{tabular}

during the potential sweep in potentiodynamic conditions possibly allows the formation of a highly ordered and more stable oxides ${ }^{19}$. The higher stability of potentiodynamic oxides may be observed in Table 1. Surfaces obtained potentiodinamically presented OCP at $-38.4 \mathrm{mV}\left(\mathrm{H}_{3} \mathrm{PO}_{4}\right)$ and $-22.8 \mathrm{mV}\left(\mathrm{H}_{2} \mathrm{SO}_{4}\right)$ whereas potentiostatic oxides showed $\mathrm{OCP}$ at $-67.2 \mathrm{mV}\left(\mathrm{H}_{3} \mathrm{PO}_{4}\right)$ and $-42.3 \mathrm{mV}\left(\mathrm{H}_{2} \mathrm{SO}_{4}\right)$. Although the potential was applied for one hour in potentiostatic condition, the results indicated that time have no effect on the measured equilibrium potential. Thus, the anodic oxide growth on tantalum surfaces follows the High Field Model and its growth rate is mainly function of the applied potential and constants that are typical to every oxide ${ }^{20}$. As described in Marino's research ${ }^{20}$ with anodic charges of the Ti-oxide growth, the anodization rate was determined by electrochemical methods and was found to be $2.5 \mathrm{~nm} / \mathrm{V}$.

Regarding the thermodynamic stability of the oxides grown potentiostatically at $5 \mathrm{~V}$ and $20 \mathrm{~V}$, Table 1 presents $\mathrm{OCP}$ at $-67.2 \mathrm{mV}\left(\mathrm{H}_{3} \mathrm{PO}_{4}\right)$ and $-42.3 \mathrm{mV}\left(\mathrm{H}_{2} \mathrm{SO}_{4}\right)$ for oxides grown at $5 \mathrm{~V}$ and $-17.3 \mathrm{mV}\left(\mathrm{H}_{3} \mathrm{PO}_{4}\right)$ and $-5.42 \mathrm{mV}\left(\mathrm{H}_{2} \mathrm{SO}_{4}\right)$ for oxides grown at $20 \mathrm{~V}$. The higher stability of oxides grown at $20 \mathrm{~V}$ may be associated to its larger thickness $(20 \mathrm{~nm}$ for $5 \mathrm{~V}$ and $77 \mathrm{~nm}$ for $20 \mathrm{~V}$ ). A thicker oxide may have a higher resistive behavior ${ }^{21}$.

The thermodynamical stability of oxides grown in different acidic electrolytes may be compared. Independently of the electrochemical method or applied potential, oxides grown in $\mathrm{H}_{2} \mathrm{SO}_{4}$ shown more positive equilibrium potential and consequently, higher thermodynamical stability. As described by several researches ${ }^{10,13}$, the oxides grown in dilute $\mathrm{H}_{2} \mathrm{SO}_{4}$ are homogeneous and shown least amounts of $\left(\mathrm{SO}_{4}\right)^{2-}$ incorporation on its structure. Tantalum oxides grown, even in dilute, $\mathrm{H}_{3} \mathrm{PO}_{4}$ electrolytes shown considerable amounts of $\left(\mathrm{PO}_{4}\right)^{3-}$ incorporated to the oxide, enabling the formation of less stable dual layer mixed oxide ${ }^{10-13}$.

By the OCP data (Table 2) was possible to study the dissolution process of tantalum anodic oxides in aggressive fluid media. The tantalum oxide layer presented more positive equilibrium potential values, compared to pure tantalum, independently of the acid electrolyte. It indicates that the oxidized surfaces are more stable due to the oxide presence. When the immersion time of the oxides was 15 days, the equilibrium potential becomes more negative around $-34.7 \mathrm{mV}$ (sulphate media) and $-65.4 \mathrm{mV}$ (phosphate media). The same tendency occurs with $\mathrm{Ta} / \mathrm{Ta}_{2} \mathrm{O}_{5}(20 \mathrm{~V}-1 \mathrm{~h})$ in artificial blood, as -73.2 and $-109 \mathrm{mV}$ after 60 days. The oxidized surface remains stable even after 60 days considering that pure tantalum has the lowest stability with an OCP of $-660 \mathrm{mV}$. This result indicates that $\mathrm{Ta}_{2} \mathrm{O}_{5}$ is a highly stable oxide, resistant to dissolution/corrosion process in a simulated corporal aggressive media. Tantalum oxides obtained in sulphate media presented a higher thermodynamical stability and this tendency was kept during the whole experiment time.

The tantalum oxide grown in $\mathrm{H}_{3} \mathrm{PO}_{4}\left(1 \mathrm{~mol} . \mathrm{L}^{-1}\right)$ may present a dual layer structure ${ }^{7}$, which may contribute to its lower stability ${ }^{8}$. Many authors described ${ }^{10-13}$ that the phosphate ions could be incorporated to the tantalum oxide structure and consequently a mixed oxide of tantalum and phosphorus are formed. This result agrees to the XPS spectra of the samples of $\mathrm{Ta}_{2} \mathrm{O}_{5}$ obtained in $\mathrm{H}_{3} \mathrm{PO}_{4}$ of this research, indicating that 
Table 2. OCP values for bare tantalum and its oxides obtained in $\mathrm{H}_{2} \mathrm{SO}_{4}$ and $\mathrm{H}_{3} \mathrm{PO}_{4}\left(1\right.$ mol. $\left.\mathrm{L}^{-1}\right)$ before and after immersion in artificial blood by 15,30 and 60 days.

\begin{tabular}{cccc}
\hline \multirow{2}{*}{$\begin{array}{c}\text { Immersion time in artificial } \\
\text { blood at } \mathbf{3 7}{ }^{\circ} \mathbf{C} \text { (days) }\end{array}$} & Bare Tantalum & $\mathbf{T a}_{\mathbf{2}} \mathbf{O}_{\mathbf{5}} / \mathbf{H}_{\mathbf{2}} \mathbf{S O}_{\mathbf{4}}\left(\mathbf{1} \mathbf{~ m o l . L}^{-1}\right)$ & $\mathbf{T a}_{\mathbf{2}} \mathbf{O}_{\mathbf{5}} / \mathbf{H}_{\mathbf{3}} \mathbf{P O}_{\mathbf{4}}\left(\mathbf{1} \mathbf{~ m o l . L}^{-1}\right)$ \\
\cline { 2 - 4 } & -660 & -5.42 & -17.3 \\
15 & & -34.7 & -65.4 \\
30 & & -52.8 & -96.5 \\
60 & & -73.2 & -109 \\
\hline
\end{tabular}

possibly has incorporated phosphorus species. Mixed oxides has variable structure and chemical composition along its thickness, with a compact inner layer composed mainly of stoichiometric $\mathrm{Ta}_{2} \mathrm{O}_{5}$ and a porous outer layer composed of $\mathrm{Ta}_{2} \mathrm{O}_{5}$ and incorporated phosphates ${ }^{10-13}$. Those incorporated phosphates may be interpreted as point defects of chemical inhomogeneity that increases its chemical reactivity and its susceptibility to dissolution/corrosion in aggressive media ${ }^{11}$. Researchers ${ }^{12}$ studied the dissolution resistance of tantalum oxide layers in aggressive media ( $\mathrm{F}^{-}$ions) and also noticed that the dissolution rate of mixed oxides is superior if compared to stoichiometric $\mathrm{Ta}_{2} \mathrm{O}_{5}$. Possibly, the outer layer of the oxide grown in $\mathrm{H}_{3} \mathrm{PO}_{4}\left(1\right.$ mol. $\left.\mathrm{L}^{-1}\right)$ provides a higher reactivity in aggressive media and it may be detected by its more negative equilibrium potential value.

Lower elastic modulus is preferable for metallic biomaterials since it helps to avoid phenomenon of stress shielding. It happens when the implant supports most of the loads, since it has a higher elastic modulus when compared to the human bone ( $30 \mathrm{GPa})$, leaving the bone underused. Stress shielding may lead to bone reabsorption, loosening of the implant or even another bone fracture ${ }^{22}$. A lower elastic modulus material supports a uniform distribution of load between implant and bone ${ }^{23}$. Pure tantalum elastic modulus is about $186 \mathrm{GPa}$, which is higher than the $110 \mathrm{GPa}$ of pure titanium, but yet lower than $220 \mathrm{GPa}$ and $190 \mathrm{GPa}$ of cobalt-chrome alloys and some stainless steels used for implants, respectively. By the instrumented indentation tests, the elastic modulus of the tantalum oxides obtained potentiostatically in $\mathrm{H}_{2} \mathrm{SO}_{4}$ e $\mathrm{H}_{3} \mathrm{PO}_{4}$ was measured Firstly, it was analyzed the $\mathrm{Ta}_{2} \mathrm{O}_{5}$ film obtained in sulfate ions containing media. The analysis of Figure 6 allows us to assume that there is a relation between the depth of contact and the elastic modulus, indicating that the obtained oxide should be homogeneous. Higher loads resulted in deeper penetrations and therefore a greater influence of the substrate in the measure. As there is a considerable influence of the substrate even in the first measure, in about $30 \mathrm{~nm}$, it cannot be affirmed that the elastic modulus of the film is equal to the first indentation, however, it can certainly be stated that the elastic modulus is lower than $186 \mathrm{GPa}$ of the substrate. With increasing loads and deeper penetrations, the measured elastic modulus increases due to the higher contribution of the substrate in the measure, approaching asymptotically to values close to the substrate. Tests in tantalum oxide obtained in phosphate medium showed reduced elastic modulus, of the order of $125 \mathrm{GPa}$ at the first indentations, indicating that this material has a lower elastic modulus compared to the substrate. The incorporation of electrolyte species to the outermost layer of the oxide promotes the formation

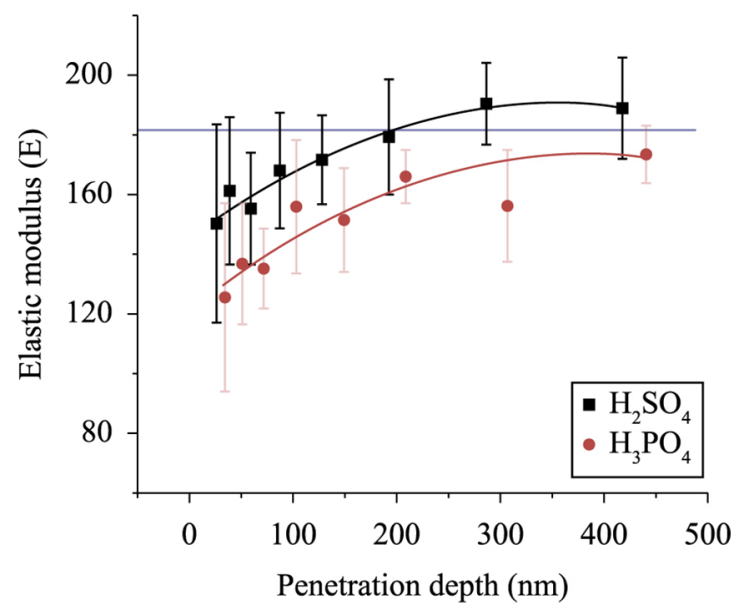

Figure 6. Elastic modulus as function of the penetration depth with a Berkovich tip in tantalum oxides obtained potentiostatically $20 \mathrm{~V}$ (1 h) in $\mathrm{H}_{2} \mathrm{SO}_{4}$ and $\mathrm{H}_{3} \mathrm{PO}_{4}\left(1 \mathrm{~mol} . \mathrm{L}^{-1}\right)$. The straight line represents the metallic tantalum elastic modulus (186 GPa).

of a mixed oxide of tantalum and phosphorus. This bilayer oxide apparently has a lower elastic modulus because it was less compact. Summarizing, the acidic electrolyte used for potentiostatic tantalum anodizing influences the mechanical properties of $\mathrm{Ta}_{2} \mathrm{O}_{5}$ obtained anodically. The formation of a bilayer tantalum oxide (in $\mathrm{H}_{3} \mathrm{PO}_{4} 1 \mathrm{~mol} . \mathrm{L}^{-1}$ ), which may vary in chemical composition and densification along its thickness, can promote a lower elastic modulus on its outer layer. An oxide of uniform composition and dense throughout its thickness, as the oxide obtained in $\mathrm{H}_{2} \mathrm{SO}_{4}\left(1 \mathrm{~mol} . \mathrm{L}^{-1}\right)$, tends to have a higher elastic modulus, even in small penetrations. It cannot be stated precisely the elastic modulus of the oxide, since the contribution of the substrate measured, however, it can be confirmed that tantalum oxides obtained in both acidic electrolytes have lower elastic modulus than the substrate and therefore anodization can be considered a good surface treatment for bone apposition.

Scratching tests were carried out to end loads of 10, 30 and $50 \mathrm{mN}$, however, only the scratches with load of $50 \mathrm{mN}$ were observed. Although the scratches undertaken to $50 \mathrm{mN}$ were noticeable, there was no tearing of the surface oxide, indicating that the anodic oxides obtained in the employed electrochemical conditions are strongly adherent to the metal substrate of tantalum. The micrograph of the scratch performed on the $\mathrm{Ta}_{2} \mathrm{O}_{5}$ anodic film obtained potentiostatically in $\mathrm{H}_{3} \mathrm{PO}_{4}\left(1 \mathrm{~mol} . \mathrm{L}^{-1}\right)$ is presented in Figure 7 . The original topographic profile and the residual scratch of the sample (after scratching) are presented in Figure 8. These profiles 


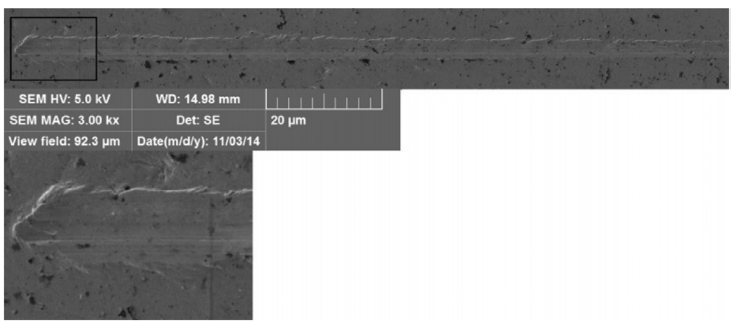

Figure 7. SEM of the $50 \mathrm{mN}$ scratch on the $20 \mathrm{~V}(1 \mathrm{~h}) \mathrm{H}_{3} \mathrm{PO}_{4}$ $\left(1 \mathrm{~mol} . \mathrm{L}^{-1}\right)$. Image obtained with a magnification of $3000 \mathrm{x}$.

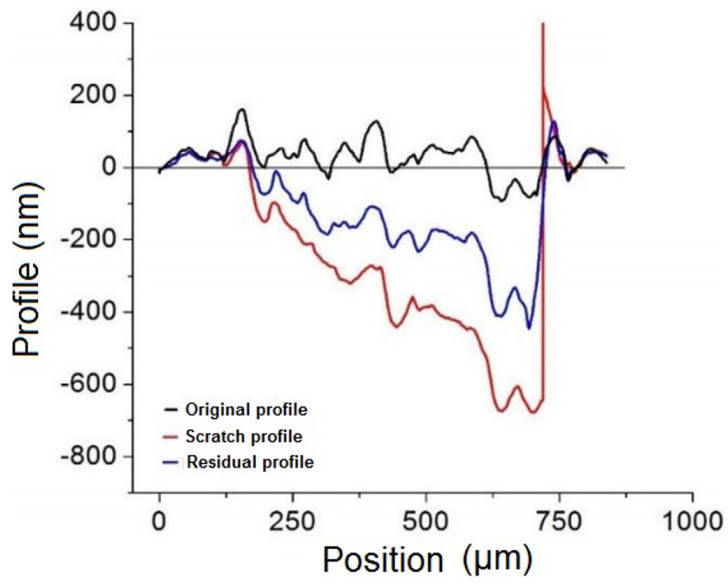

Figure 8. Original, scratch and residual profiles of the $20 \mathrm{~V}(1 \mathrm{~h})$ $\mathrm{H}_{3} \mathrm{PO}_{4}\left(1 \mathrm{~mol} . \mathrm{L}^{-1}\right)$ tantalum oxide.

were obtained using a profilometer of the equipment used for scratching. For topographic profiles and the profile analysis after scratch (residual profile), it can be seen that the $\mathrm{Ta} / \mathrm{Ta}_{2} \mathrm{O}_{5}$ material possess great capacity for deformation without fracture, i.e, the material is plastically deformed but also elastically returns to a state of low strain.

The scratch performed in the tantalum oxide obtained in $\mathrm{H}_{2} \mathrm{SO}_{4}$, (Figure 9) similarly to the scratch showed in tantalum oxide obtained in $\mathrm{H}_{3} \mathrm{PO}_{4}$, does not indicate tearing of the film to the maximum load of $50 \mathrm{mN}$. Again, the oxide was highly adherent to the substrate, with capacity of deformation without fracture. In both cases (Figure 8 and Figure 10), the residual profile is an intermediate profile between the original profile and the scratch profile, once again indicating that the tantalum oxide in the form of thin film $(\sim 77 \mathrm{~nm})$ has high deformation capacity without fracture, i.e, the material has residual plastic deformation but elastically returns to a closer form to the original. In addition, by the profiles can be seen that the load used was heavy enough so that the substrate was also deformed.

The analysis of microscopy with the topographic profile, allows to compare these results to studies already described in the literature ${ }^{24,25}$. Eliezer \& Brandon ${ }^{24}$ apud Bubar \& Vermilyea $^{25}$ observed plastic deformation around $50 \%$ for galvanostatic anodic films of $\mathrm{Ta}_{2} \mathrm{O}_{5}$ obtained in acidic electrolytes, which indicates a highly adherent oxide for this feature in the proposed dimensions (thin film). In another research, Dunn ${ }^{26}$ observed through lamination that tantalum samples with $\mathrm{Ta}_{2} \mathrm{O}_{5}$ films grown galvanostatically in acidic

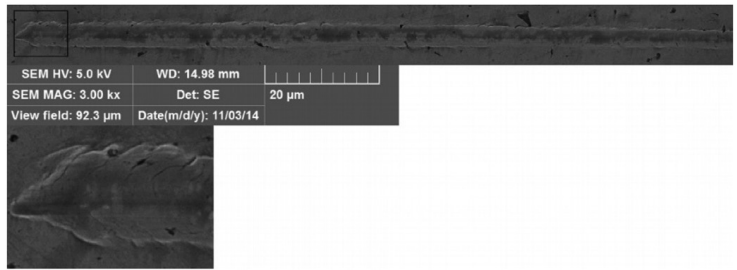

Figure 9. SEM of the $50 \mathrm{mN}$ scratch on the $20 \mathrm{~V}(1 \mathrm{~h}) \mathrm{H}_{2} \mathrm{SO}_{4}$ $\left(1 \mathrm{~mol} . \mathrm{L}^{-1}\right)$. Image obtained with a magnification of $3000 \mathrm{x}$.

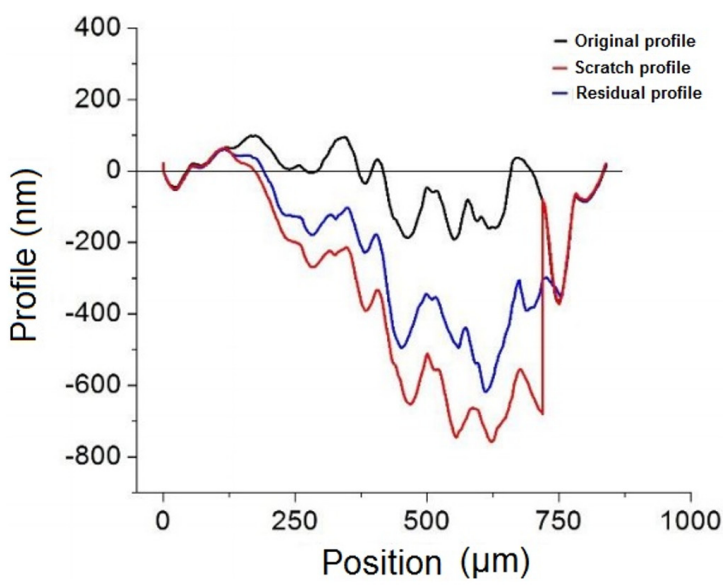

Figure 10. Original, scratch and residual profiles of the $20 \mathrm{~V}(1 \mathrm{~h})$ $\mathrm{H}_{2} \mathrm{SO}_{4}\left(1 \mathrm{~mol} . \mathrm{L}^{-1}\right)$ tantalum oxide.

electrolytes had high deformation capacity. The researcher also noted that the thickness of the tantalum oxide decreases evenly throughout the specimen, without fracture and without the detachment of the film, indicating that this material support plastic deformation ${ }^{26,27}$. Analyzing the images from SEM in Figures 7 and 9 once again, it is noted that the scratches on samples of tantalum oxide obtained in both acidic electrolytes are very similar. It is possible that higher porosities content in the outer layer of a tantalum bilayer oxide obtained in phosphate media could make deformation of the film less uniform and more subject to fractures, however, this behavior could not be observed by the SEM images. It is possible that the small thickness of the oxide layer $(\sim 77 \mathrm{~nm})$ has precluded this analysis.

\section{Conclusions}

The electrochemical growth of compact tantalum oxides by different electrochemical methods, potentials and acidic electrolytes is possible and reproducible. Phosphate ions from the electrolyte were possibly incorporated and a mixed tantalum/phosphorus oxide was formed. Besides, a bilayer oxide may be grown in phosphate media, with a compact inner layer and a reactive and porous outer layer. The greater chemical reactivity of the outer layer could facilitate the spontaneous dissolution rate of tantalum oxide in aggressive media as artificial blood. The tantalum oxides grown in sulphate media, in higher potentials and by potentiodynamic electrochemical method presented higher thermodinamical 
stability due to its chemical homogeneity, higher thickness and structural organization, respectively. Regarding the mechanical properties: the tested tantalum oxides presented lower elastic modulus than metallic tantalum (186 GPa). This result indicates that the tantalum oxide might be a more suitable substrate for bone-implant contact. Tantalum oxides obtained in $\left(\mathrm{PO}_{4}\right)^{3-}$ media presented lower elastic modulus, which confirms the possibility of the formation of a more porous oxide in the outer layer of this oxide. Bilayer oxides

\section{References}

1. Elias CN, Lima JHC, Valiev R and Meyers MA. Biomedical applications of titanium and its alloys. Overview Biological Materials Science. 2008; 60(3):46-49.

2. Black J. Biological performance of tantalum. Clinical Materials. 1994; 16(3):167-173. http://dx.doi.org/10.1016/02676605(94)90113-9. PMid:10172264.

3. Mareci D, Chelariu R, Gordin DM, Ungureanu G and Gloriant T. Comparative corrosion study of Ti-Ta alloys for dental applications. Acta Biomaterialia. 2009; 5(9):3625-3639. http:// dx.doi.org/10.1016/j.actbio.2009.05.037. PMid:19508903.

4. Trillo EA, Ortiz C, Dickerson P, Villa R, Stafford SW and Murr LE. Evaluation of mechanical and corrosion biocompatibility of TiTa alloys. Journal of Materials Science, Materials in Medicine. 2001; 12(4):283-292. http://dx.doi.org/10.1023/A:1011210101895. PMid:15348288.

5. Souza KA and Robin A. Preparation and characterization of Ti-Ta alloys for application in corrosive media. Materials Letters. 2003; 57(20):3010-3016. http://dx.doi.org/10.1016/ S0167-577X(02)01422-2.

6. Starikov VV, Starikova SL, Mamalis AG, Lavrynenko SN and Ramsden JJ. The application of niobium and Tantalum oxides for implant surface passivation. Journal of Biological Physics and Chemistry. 2007; 7(4):141-145. http://dx.doi. org/10.4024/40704.jbpc.07.04.

7. Diamanti MV and Pedeferri MP. Effect of anodic oxidation parameters on the Titanium oxides formation. Corrosion Science. 2007; 49(2):939-948. http://dx.doi.org/10.1016/j. corsci.2006.04.002.

8. Ferreira EA, Rocha-Filho RC, Biaggio SR and Bocchi N. Corrosion resistance of the Ti-50Zr at.\% alloy after anodization in different acidic electrolytes. Corrosion Science. 2010; 52(12):4058-4063. http://dx.doi.org/10.1016/j.corsci.2010.08.021.

9. Pyun S and Hong M. A model describing the growth kinetics of passivating oxide film prepared under potentiostatic conditions. Electrochimica Acta. 1992; 37(2):327-332. http://dx.doi. org/10.1016/0013-4686(92)85019-H.

10. Randall JJ Jr, Bernard WJ and Wilkinson RR. A radiotracer study of the composition and properties of anodic oxide films on Tantalum and niobium. Electrochimica Acta. 1965; 10(2):183201. http://dx.doi.org/10.1016/0013-4686(65)87018-9.

11. Amsel G, Cherki C, Feuillade G and Nadai JP. The influence of the electrolyte on the composition of 'anodic oxide films' on Tantalum. Journal of Physics and Chemistry of Solids. 1969; 30(9):2117-2134. http://dx.doi.org/10.1016/0022-3697(69)901371.

12. Shimizu K, Brown GM, Habazaki H, Kobayashi K, Skeldon P, Thompson GE, et al. Direct observation of anodic oxide films formed on Tantalum in concentrated phosphoric and sulphuric acid solutions. Corrosion Science. 1998; 40(6):963-973. http:// dx.doi.org/10.1016/S0010-938X(98)00035-3.

13. Sloppy JD, Lu Z, Dickey EC and MacDonald DD. Growth mechanism of anodic Tantalum pentoxide formed in phosphoric may influence mechanical properties of tantalum anodic films. The scratching tests showed that all anodic films are highly adherent to the metallic surface, not being pulled of even in higher loads $(50 \mathrm{mN})$. The obtained results indicates that the system $\mathrm{Ta} / \mathrm{Ta}_{2} \mathrm{O}_{5}$ is a stable material, presenting high chemical inertia in body simulated corrosive media, high adherence to the metallic substrate and a lower elastic modulus than the metallic tantalum, indicating that it might be applied as a biomaterial.

acid. Electrochimica Acta. 2013; 87:82-91. http://dx.doi. org/10.1016/j.electacta.2012.08.014.

14. Oliver WC and Pharr GM. Measurement of hardness and elastic modulus by instrumented indentation: advances in understanding and refinements to methodology. Journal of Materials Research. 2004; 19(1):3-20. http://dx.doi.org/10.1557/jmr.2004.19.1.3.

15. Ho SF, Contarini S and Rabalais JW. Metallization channels in ion-induced decomposition of molybdates and niobates. Chemical Physics Letters. 1987; 13(2):171-175. http://dx.doi. org/10.1016/0009-2614(87)87044-6.

16. Sarma DD and Rao CNR. XPES studies of oxides of secondand third-row transition metals including rare earths. Journal of Electron Spectroscopy and Related Phenomena. 1980; 20(1):25-45. http://dx.doi.org/10.1016/0368-2048(80)85003-1.

17. Franke R, Chásse T, Streubel $P$ and Meisel A. Auger parameters and relaxation energies of phosphorus in solid compounds. Journal of Electron Spectroscopy and Related Phenomena. 1991; 56(4):381-388. http://dx.doi.org/10.1016/0368-2048(91)85035-R.

18. Marino CEB, Nascente PAP, Biaggio SR, Rocha-Filho RC and Bocchi N. XPS characterization of anodic titanium oxide films grown in Phosphate buffer solution. Thin Solid Films. 2004; 468(1-2):109-112. http://dx.doi.org/10.1016/j.tsf.2004.05.006.

19. Blackwood DJ and Chooi SKM. Stability of protective oxide films formed on a porous titanium. Corrosion Science. 2002; 44(3):395-405. http://dx.doi.org/10.1016/S0010-938X(01)00080-4.

20. Marino CEB, Oliveira EM, Rocha-Filho RC and Biaggio SR. On the stability of thin-anodic-oxide films of titanium in acid phosphoric media. Corrosion Science. 2001; 43(8):1465-1476. http://dx.doi.org/10.1016/S0010-938X(00)00162-1.

21. Mardare A.I, Ludwig A, Savan A, Hassel A.W. Properties of anodic oxides grown on a Hafnium-Tantalum-Titanium thin film library. Science and Technology of Danced Materials. $2014 ; 15$.

22. Niinomi M, Nakai M and Hieda J. Development of new metallic alloys for biomedical applications. Acta Biomaterialia. 2012; 8(11):3888-3903. http://dx.doi.org/10.1016/j.actbio.2012.06.037. PMid:22765961.

23. Niinomi M. Recent metallic materials for biomedical applications. Metallurgical and Materials Transactions. A, Physical Metallurgy and Materials Science. 2002; 33(3):477-486. http://dx.doi. org/10.1007/s11661-002-0109-2.

24. Eliezer D and Brandon DG. The mechanical properties of anodic tantalum oxide films. Thin Solid Films. 1972; 12(2):319-323. http://dx.doi.org/10.1016/0040-6090(72)90096-X.

25. Bubar SF and Vermilyea DA. Deformation of anodic oxide films. Journal of the Electrochemical Society. 1966; 113(9):892-895. http://dx.doi.org/10.1149/1.2424149.

26. Dunn CG. Information on anodic oxide on valve metals: oxide growth at constant rate of voltage increase. Journal of the Electrochemical Society. 1969; 115(2):219-226. http://dx.doi. org/10.1149/1.2411090.

27. Young L. Physics of thin films. New York: Academic Press; 1971. v. 6, Anodic Oxide Films. 